\title{
Phytase-producing Bacillus sp. inoculation increases phosphorus availability in cattle manure
}

\author{
D. Menezes-Blackburn ${ }^{1,2}$, N.G. Inostroza ${ }^{2}$, L. Gianfreda ${ }^{3}$, R. Greiner ${ }^{4}$, M.L. Mora ${ }^{2}$, M.A. \\ Jorquera $^{2 *}$ \\ ${ }^{1}$ Lancaster Environmental Center, University of Lancaster, Lancaster LA1 4YQ, UK. ${ }^{2}$ Scientific and \\ Technological Bioresource Nucleus, Universidad de La Frontera, Ave. Francisco Salazar 01145, \\ Temuco, Chile. ${ }^{3}$ Dipartimento di Agraria, Università di Napoli Federico II, Portici, Italy. ${ }^{4}$ Department \\ of Food Technology and Bioprocess Engineering, Max Rubner-Institut, Federal Research Institute \\ of Nutrition and Food, Karlsruhe, Germany.*Correspondence author: milko.jorquera@ufrontera.cl
}

\begin{abstract}
Organic wastes rich in phosphorus $(\mathrm{P})$ are considered an alternative to decrease the dependence on chemical $\mathrm{P}$ fertilization in crops and pastures. Microbial inoculants are being studied as a tool to increase plant $\mathrm{P}$ availability in organic wastes. In this study, we explore the effect of inoculation with Bacillus sp. MQH-19 (a native phytase-producing bacterium) on the release of inorganic phosphorus (Pi) in cattle manure with low available $\mathrm{P}$ but a high total $\mathrm{P}$ content. Bacteria inoculation resulted in a higher release of $\mathrm{Pi}\left(8 \%\right.$ in $\mathrm{NaHCO}_{3}$ and $13 \%$ in $\mathrm{NaOH}-\mathrm{EDTA}$ extracts) compared with that of uninoculated manure $\left(0.7 \%\right.$ in $\mathrm{NaHCO}_{3}$ and $0.1 \%$ in $\mathrm{NaOH}-\mathrm{EDTA}$ extracts). However, a greater amount of Pi was released in inoculated manure supplemented with phytate (47\% in $\mathrm{NaHCO}_{3}$ and $117 \%$ in $\mathrm{NaOH}-\mathrm{EDTA}$ extracts) compared with that of uninoculated manure supplemented with phytate $\left(30 \%\right.$ in $\mathrm{NaHCO}_{3}$ and $15 \%$ in $\mathrm{NaOH}-\mathrm{EDTA}$ extracts). In addition, the use of denaturing gradient gel electrophoresis (DGGE) and quantitative PCR (qPCR) revealed that the bacterial community structure in manure was affected by inoculation and that the prevalence of Bacillus sp. MQH-19 decreased during incubation (6 days). This study demonstrates that Pi availability in cattle manure can be increased by phytase-producing bacteria inoculation. Phytase-producing bacteria inoculation might represent an attractive strategy to increase $\mathrm{P}$ availability in agricultural wastes, which are used as organic fertilizers in crops and pastures.
\end{abstract}

Keywords: Bacillus, cattle manure, phytate, phytase-producing bacteria, phosphorus

\section{Introduction}

Phytate is the main form of phosphorus $(\mathrm{P})$ storage in plant and the major constituent of organic $\mathrm{P}(\mathrm{Po})$ fraction in seeds. Although ruminants have natural phytase activity in their digestive tract, a large amount of phytase-labile $\mathrm{P}$ passes undigested, which leads to animal manures containing a high total $\mathrm{P}$ (Pt) content, particularly organic $\mathrm{P}$ forms, such as phytate (He et al., 2006; Menezes-Blackburn et al., 2013). Animal manures and other agricultural wastes are commonly used as organic fertilizers by farmers; 
however, during their storage and degradation, diverse changes in their physico-chemical properties, $P$ availability and microbial populations occur (Smith and Collins 2007; Fuentes et al., 2009). When animal manure reaches a soil environment, phytate strongly interacts with soil minerals and becomes highly unavailable as a $\mathrm{P}$ source for nutrition of plants and microorganisms (George et al., 2007; MenezesBlackburn et al., 2013).

Currently, most $\mathrm{P}$ fertilizers are manufactured from rock phosphate, which in turn, are a non-renewable and limited mineral resource, and major attention has been given to improve plant access to the $\mathrm{P}$ pool contained in organic wastes, such as cattle manure (Abelson 1999; Richardson et al., 2006; MenezesBlackburn et al., 2013). Additionally, it has been proposed that composting of organic wastes enriched with bacteria facilitates the release of phosphate groups from inorganic $(\mathrm{Pi})$ and Po forms, which increases the $\mathrm{P}$ availability to plants (Zayed and Abdel-Motaal, 2005). In this context, commercial phytases, such as histidine acid phytases, have been successfully tested as $\mathrm{P}$ biofertilizers in acid soils but were shown to not improve $\mathrm{P}$ availability in animal manure (MenezesBlackburn et al., 2011; Menezes-Blackburn et al., 2014). Indeed, commercial phytases were selected and engineered to act in the acid environment of animal stomachs (Lei and Porres 2003; Greiner and Konietzny 2011; Menezes-Blackburn and Greiner 2014). Manures are generally slightly alkaline, and therefore, bacterial alkaline $\beta$-propeller phytases (BPP) would be the most suitable type of phytases for application in this environment (Jorquera et al., 2008a; Acuña et al., 2011).

During the last few years, our group has isolated several phytate-utilizing bacteria from cattle manure and soil environments (Jorquera et al., 2008b; Fuentes et al., 2009; Jorquera et al., 2011; Martinez et al., 2011). However, the application of these strains to improve Po hydrolysis in manure with a concomitant increase in $\mathrm{P}$ availability for plants requires further evaluation. The primary concerns regarding the use of these bacteria as manure inoculants are the inoculum prevalence, phytase expression levels and the activity of their phytases in a suitable $\mathrm{pH}$ range. Therefore, the objectives of this work were to evaluate the effect of phytase-producing bacteria inoculation on $\mathrm{P}$ release in cattle manure with low available $\mathrm{P}$ but high Pt contents. In addition, the bacterial community structure and inoculum prevalence were evaluated by denaturing gradient gel electrophoresis (DGGE) and quantitative PCR (qPCR) using 16S rRNA and $\beta$-BPP as gene targets.

\section{Materials and Methods}

\subsection{Cattle manure sample}

Cattle manure with low available $\mathrm{P}$ was collected in Cerro Azul farm at Rio Blanco, southern Chile $\left(40^{\circ} 20^{\prime} \mathrm{S} ; 7^{\circ} 35^{\prime} \mathrm{W}\right)$. In this farm, animals are kept confined during winter, and the accumulated manure mixture (dung, straw, feed and soil) was kept under open field storage yard conditions for at least one year before this experiment. The collected manure was transported to the laboratory, air-dried, homogenized, passed through a 2-mm sieve and subjected to analysis to determine its chemical properties. Total $\mathrm{P}$ and inorganic $\mathrm{P}(\mathrm{Pi})$ were estimated according to Fuentes et al. (2009) using the sequential $\mathrm{P}$ fractionation procedure of Hedley et al. (1982) with modifications described by Ajiboye et al. (2004). Briefly, $0.3 \mathrm{~g}$ of manure sample was shaken with $30 \mathrm{ml}$ of sequential extraction solutions (distilled water, $0.5 \mathrm{M} \mathrm{NaHCO}_{3}$, $0.1 \mathrm{M} \mathrm{NaOH}$-EDTA and $1 \mathrm{M} \mathrm{HCl}$ ). Each fraction was digested using nitric-perchloric acid digestion, and the concentration of $\mathrm{P}$ was measured by spectrophotometry at $880 \mathrm{~nm}$. The $\mathrm{pH}$ was measured 
in 1:2.5 soil/ deionized water suspensions. Nitrogen (N) was measured using the Kjeldahl method, and organic carbon (C) was measured according to protocols described by Sparks (1996). The following are the properties of cattle manure that were used: $60.8 \mathrm{mg} \mathrm{Pi} \mathrm{kg}{ }^{-1}, 2341 \mathrm{mg} \mathrm{Pt} \mathrm{kg}{ }^{-1}, \mathrm{pH} 6.2,1.4 \%$ of $\mathrm{N}$, $22.7 \%$ of $\mathrm{C}$ and a $\mathrm{C}: \mathrm{N}$ ratio of 16.2 .

\subsection{Manure inoculation assay}

Bacillus sp. MQH-19 was chosen for the inoculation assay because it does the following: i) produces phytase activity in the presence of phytate (Jorquera et al., 2011), ii) increases extracellular Pi concentrations when grown in medium supplemented with phytate as the sole P source (Acuña et al., 2011) and iii) increases $\beta$-propeller phytase gene expression when grown in a medium or soil microcosm supplemented with phytate (Jorquera et al., 2013).

To examine the effects of Bacillus sp. MQH-19 inoculation on the $\mathrm{P}$ release in cattle manure, 10 $\mathrm{g}$ of manure was placed in sterile $50-\mathrm{mL}$ Falcon tubes and inoculated with Bacillus sp. MQH-19 at a final concentration of $10^{9}$ cells $\mathrm{g}^{-1}$ of manure. For inoculation, Bacillus sp. MQH-19 cells were taken from fresh culture broth and washed three times with sterile saline solution $(0.85 \% \mathrm{NaCl})$. Additionally, Falcon tubes containing $10 \mathrm{~g}$ of manure were supplemented with $0.5 \mathrm{mM}$ Na-phytate $\mathrm{g}^{-1}$ of manure and inoculated as described above. Controls without bacterial inoculation were also performed for manure with and without phytate supplementation. The manure moisture levels were adjusted to $80 \%$ of the water-holding capacity, after which, the tubes were incubated for 6 days at $30^{\circ} \mathrm{C}$. The Pi concentration was determined before and after incubation in $\mathrm{H}_{2} \mathrm{O}$, $\mathrm{NaHCO}_{3}$ and NaOH-EDTA extracts as previously described (Menezes-Blackburn et al., 2014).

\subsection{Bacterial community structure}

The bacterial community structure in manure incubation assay was examined at 0,3 and 6 days by DGGE as described by Jorquera et al. (2010). Total DNA was extracted using a Power Soil® DNA Isolation Kit (Mo Bio, Inc.) according to the manufacturer's instructions. The primers, EUB933fGC and EUBr1387 (Iwamoto et al., 2000), were used to amplify $\sim 450 \mathrm{bp}$ DNA fragments of bacterial 16S rRNA genes. The DGGE electrophoresis was run for $10 \mathrm{~h}$ at $100 \mathrm{~V}$, and $35-65 \%$ gradient (urea and formamide) gels were stained with SYBR Gold (Molecular Probes, Invitrogen Co.) for $30 \mathrm{~min}$ and photographed on a UV transilluminator. Clustering of DGGE banding profiles using a dendrogram was performed using Phoretix 1D analysis software (Total Lab Ltd.). Based on the matrix obtained from the Phoretix 1D analysis, the changes in the presence (or absence) and abundance of bacterial groups were analyzed by principal component analysis (PCA) and the calculated Simpson, Shannon, Buzas \& Gibson and Equitability diversity indexes using PAST freeware (http://folk.uio.no/ohammer/past/).

\subsection{Prevalence of Bacillus sp. $M Q H-19$}

The prevalence of Bacillus sp. MQH-19 during the incubation manure assay was estimated as the relative abundance of BPP genes in relation to the total bacterial $16 \mathrm{~S}$ rRNA genes by qPCR according to Jorquera et al. (2013). Briefly, DNA extracts from the incubation assay were taken at 0,3 and 6 days and used for qPCR reactions with a 7300 Real Time PCR System (Applied Biosystems) using the primers, MQHf (5'-TTC CTA TCC TAC CGG GAA GC3') and MQHr (5'-TGC TTT GTA ATG TGC CGT TT-3') and Maxima ${ }^{\circledR}$ SYBR Green/ROX qPCR Master Mix (Fermentas Life Sciences) following the 
manufacturer's instructions. The qPCR conditions were as follows: an enzyme activation step at $95^{\circ} \mathrm{C}$ for $10 \mathrm{~min}$ followed by 40 cycles of $15 \mathrm{sec}$ at $95^{\circ} \mathrm{C}$ and $1 \mathrm{~min}$ of annealing plus extension. The universal primer set targeting 16S rRNA gene, Bac1369F (5'-CGG TGA ATA CGT TCY CGG-3') and Prok 1492R (5'-GGW TAC CTT GTT ACG ACT T-3') (Suzuki et al., 2000) was used to quantify the BPP gene in relation to the total bacterial DNA.
The prevalence of Bacillus sp. MQH-19 in the manure incubation assay was also estimated based on the matrix obtained from the Phoretix 1D analysis. The DGGE band of a pure culture of Bacillus sp. MQH-19 was used as reference, and Bacillus-like bands were identified within DGGE profiles of inoculated manure (IM and IM+P) (Figure 1). The relative abundance was calculated according to the fluorescence volume of the Bacillus-like band in relation to the total fluorescence volume of bands in each DGGE profile.

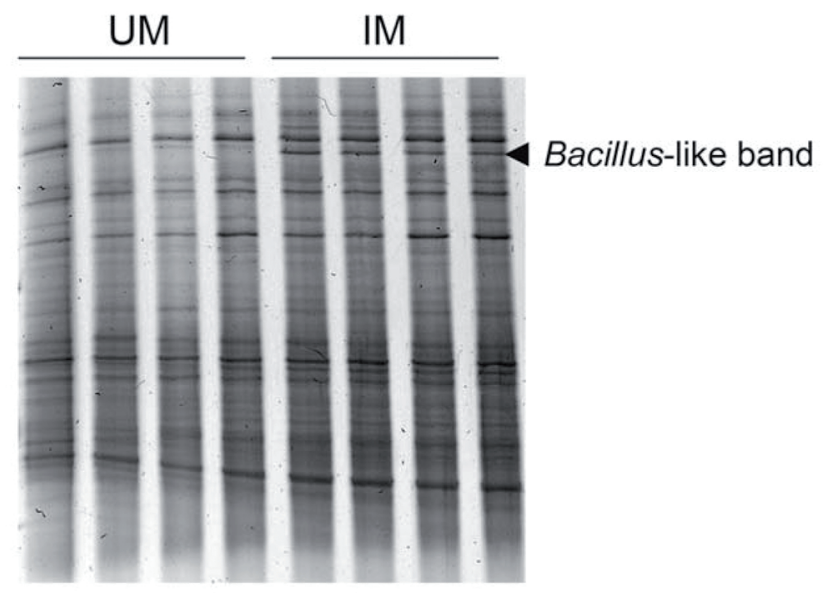

Figure 1. DGGE profiles showing Bacillus-like band used in the estimation of Bacillus sp. MQH-19 prevalence in inoculated manures. UM: uninoculated manure; IM: inoculated manure.

\subsection{Statistical analysis}

The data were analyzed by a one-way ANOVA, and comparisons were performed with the Tukey test. All analyses and experiments were performed in triplicate, and the values are given as means \pm standard errors. Differences were considered to be significant when the $P$ value was $\leq 0.05$.

\section{Results}

\subsection{Pi release in manure incubation tests}

In general, the results showed that fresh phytate supplementation significantly $(P \leq 0.05$, Tukey's test) increased Pi release in manure after 6 days of incubation. With respect to the initial Pi values, the addition of phytate to uninoculated manure (UM+P) 
increased by the Pi content by $29 \%$ and $15 \%$ in the $\mathrm{NaHCO}_{3}$ and NaOH-EDTA extracts, respectively (Table 1). In contrast, without phytate addition (UM), as mall increase in Pi was observed with values of $0.7 \%$ and $0.1 \%$ in the $\mathrm{NaHCO}_{3}$ and $\mathrm{NaOH}-\mathrm{EDTA}$ extracts, respectively. However, when phytate was supplemented to inoculated manure (IM+P), a higher increase in $\mathrm{Pi}$ was recorded with percentages of $47 \%$ and $117 \%$ of $\mathrm{Pi}$ content in the $\mathrm{NaHCO}_{3}$ and $\mathrm{NaOH}$ EDTA extracts, respectively. An increase in $\mathrm{Pi}(8 \%$ and $13 \%$ in $\mathrm{NaHCO}_{3}$ and $\mathrm{NaOH}-\mathrm{EDTA}$ extracts, respectively) was also registered in inoculated manure (IM).

Table 1. Inorganic $\mathrm{P}(\mathrm{Pi})$ in extracts from cattle manure assay after 6 days of incubation

\begin{tabular}{|c|c|c|c|c|}
\hline & \multicolumn{2}{|l|}{$\mathrm{NaHCO}_{3}$} & \multicolumn{2}{|l|}{$\mathrm{NaOH}$ EDTA } \\
\hline & $\mathrm{Pi}\left(\mathrm{mg} \mathrm{kg}^{-1}\right)$ & $\%^{\mathrm{a}}$ & $\mathrm{Pi}\left(\mathrm{mg} \mathrm{kg}^{-1}\right)$ & $\%$ \\
\hline Initial time $\uparrow$ & $60.8 \pm 0.53^{b}$ bc & & $249.20 \pm 3.59 \mathrm{c}$ & \\
\hline UM & $61.20 \pm 0.79 \mathrm{~b}$ & 0.66 & $249.49 \pm 9.70 \quad \mathrm{c}$ & 0.12 \\
\hline $\mathrm{UM}+\mathrm{P}$ & $78.73 \pm 3.09 \mathrm{a}$ & 29.50 & $285.72 \pm 12.25 \mathrm{~b}$ & 14.65 \\
\hline IM & $65.66 \pm 1.8 \mathrm{~b}$ & 8.0 & $281.84 \pm 10.45 \mathrm{~b}$ & 13.10 \\
\hline $\mathrm{IM}+\mathrm{P}$ & $89.25 \pm 1.03 \mathrm{a}$ & 46.80 & $540.63 \pm 12.90 \mathrm{a}$ & 116.95 \\
\hline
\end{tabular}

UM: uninoculated manure; UM+P: uninoculated manure plus phytate; IM: inoculated manure; IM+P: inoculated manure plus phytate. Same lowercase letter denotes no significant difference ( $\mathrm{P} \leq 0.05$; Tukey's test). ${ }^{a}$ Percentage calculated in relation to initial value of Pi in manure ( $\uparrow 0$ day). ${ }^{\mathrm{b}}$ Values represent mean \pm standard error $(n=3)$.

\subsection{Bacterial community structure}

Figure 1 shows the changes in the bacterial community structure in manure during the incubation assays revealed by DGGE. The dendrogram based on DGGE profiles showed $<80 \%$ of similarity in the community structure between uninoculated manure treatments (UM and $\mathrm{UM}+\mathrm{P}$ ) after 3 days of incubation in relation to other treatments (Figure 2, a). After 6 days of incubation, differences were also observed between uninoculated (UM and $\mathrm{UM}+\mathrm{P}$ ) and inoculated manure treatments (IM and IM+P) with a similarity $<85 \%$.
PCA analysis evidenced not only differences between uninoculated and inoculated manure treatments but also those between 3 and 6 incubation days (Figure $2, \mathrm{~b})$. With respect to diversity analysis, the indexes did not show a clear pattern. However, the Simpson, Shannon, Buzas \& Gibson and equitability diversity indexes were higher in the inoculated manure treatments (IM-6 days and IM+P-3 days) (Table 2), whereas lower values were registered in uninoculated manure treatments (UM+P-3 days and $\mathrm{UM}+\mathrm{P}-6$ days), except for the equitability index, where the lowest values were for IM+P-6 days. 
Table 2. Diversity indexes calculated on the matrix obtained from image analysis of DGGE gel by Phoretix 1D and PAST software.

\begin{tabular}{lllll}
\hline & Simpson & Shannon & Buzas \& Gibson & Equitability \\
\hline UM - 0 day & 0.9047 & 2.376 & 0.9779 & 0.9907 \\
UM+P - 0 day & 0.9078 & 2.391 & 0.9930 & 0.9971 \\
IM - 0 day & 0.9196 & 2.543 & 0.9781 & 0.9914 \\
IM+P - 0 day & 0.9192 & 2.541 & 0.9761 & 0.9906 \\
UM - 3 days & 0.9113 & 2.454 & 0.9692 & 0.9874 \\
UM+P - 3 days & 0.9098 & 2.445 & 0.9607 & 0.9839 \\
IM - 3 days & 0.9180 & 2.535 & 0.9700 & 0.9881 \\
IM+P - 3 days & 0.9185 & 2.536 & 0.9713 & 0.9887 \\
UM - 6 days & 0.9225 & 2.599 & 0.9609 & 0.9849 \\
UM+P - 6 days & 0.9212 & 2.594 & 0.9558 & 0.9829 \\
IM - 6 days & 0.9225 & 2.600 & 0.9621 & 0.9854 \\
IM+P - 6 days & 0.9197 & 2.582 & 0.9449 & 0.9785 \\
\hline
\end{tabular}

(a)

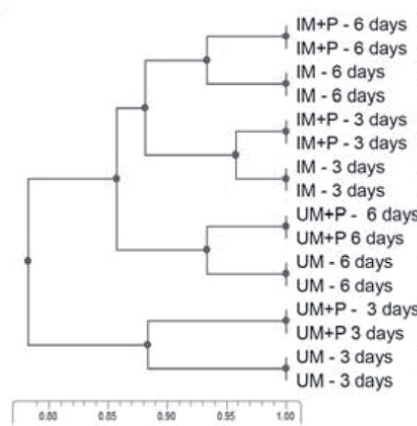

(b)

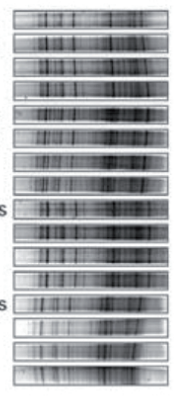

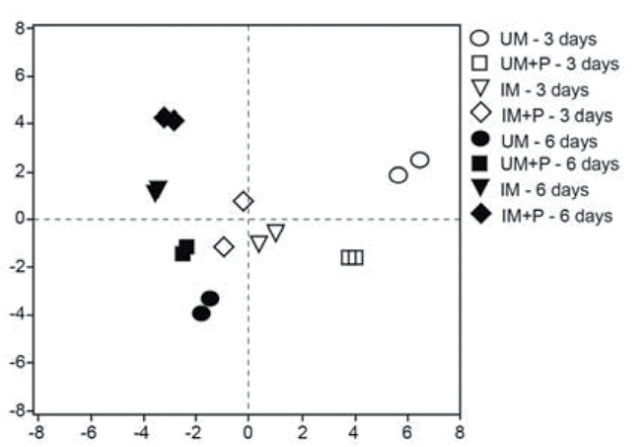

Figure 2. Dendrogram (a) and principal component analysis (b) of DGGE gel profiles (16S rRNA gene) from bacterial communities at 3 and 6 days of manure incubation at $30^{\circ} \mathrm{C}$. UM: uninoculated manure; IM: inoculated manure; UM+P: uninoculated manure plus phytate; IM+P: inoculated manure plus phytate. 


\subsection{Prevalence of Bacillus sp. MQH-19 in manure inoculation assay}

Analysis by qPCR revealed a significant decrease ( $P \leq 0.05$, Tukey's test) of Bacillus sp. MQH-19 at 3 and 6 days after inoculation (Figure 3, a). However, the inoculum prevalence was maintained between 3 and 6 days in the inoculated manure with and without supplemented phytate treatments (IM and IM+P). No positive signal for the BPP gene was observed in uninoculated manure treatments during the incubation assay (UM and $\mathrm{UM}+\mathrm{P})$. The qPCR result was confirmed when the prevalence of Bacillus-like band was estimated in the DGGE gel. The relative volume of inoculant band taken from the semiquantitative image analysis of the DGGE gel showed a continuous decrease in the inoculum during the incubation time in the IM and IM+P treatments, though was less pronounced in comparison with the qPCR analysis (Figure 3, b).
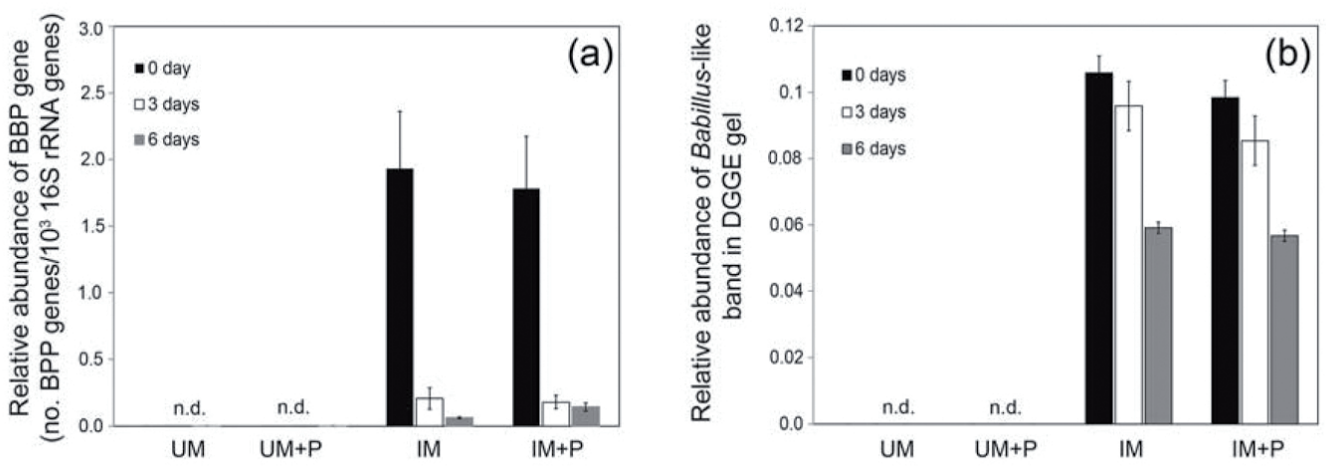

Figure 3.(a) Relative abundance by qPCR of $\beta$-propeller phytase (BPP) genes in relation to bacterial $16 \mathrm{~S}$ rRNA genes from bacterial communities at 0,3 and 6 days of manure incubation at $30^{\circ} \mathrm{C}$. (b) Relative volume of Bacillus-like band in DGGE gel in relation to band volumes of the total bacterial community. UM: uninoculated manure; UM+P: uninoculated manure plus phytate; IM: inoculated manure; IM+P: inoculated manure plus phytate. n.d..: not detected. Same lowercase letter denotes no significant difference ( $P \leq 0.05$; Tukey's test).

\section{Discussion}

Cattle manure and other agricultural wastes are often used as organic fertilizers for crops and pastures by farmers. Nevertheless, their use as P fertilizer is rather inefficient due to the large amount of unavailable Po compounds, such as phytate, which are often stabilized in soils by precipitation and adsorption processes (Menezes-Blackburn et al., 2013). Because these Po forms accumulate in soils, increased P losses are observed in runoff, which reaches water courses and causes nutrient pollution (Green et al., 2007). 
There is an increasing interest in phytase treatment of manures to hydrolyze their recalcitrant Po before they reach soils, and these Po forms become stabilized and unavailable to plants and microbes (MenezesBlackburn et al., 2013; Menezes-Blackburn et al., 2014). In our incubation assays, a higher $\mathrm{Pi}$ content (8-13\%) was observed in manure inoculated with Bacillus sp. MQH-19 (IM) compared with uninoculated manure (UM).The Bacillus sp. MQH-19 strain was found adequate for use in an inoculation manure assay to increase Po hydrolysis and Pi availability in wastes matching the observed $\mathrm{pH}$ activity profile. The sequenced BPP gene from this strain presented higher homology to the BPP gene of Bacillus amyloliquefaciens (Jorquera et al., 2011), whose activity was previously described as an extracellular alkaline phytase with an optimum $\mathrm{pH}$ of 7.5 and high substrate specificity toward phytate (Kim et al., 1998). The $\mathrm{pH}$ dependency of activity from the extracellular Bacillus sp. MQH-19 phytase was previously described by Acuña et al. (2011) with an optimum $\mathrm{pH}$ of 7.0.

The phytate in ruminant diets is partially converted to Pi during digestion due to the presence phytases in intestine mucosa and rumen microflora; nevertheless, a significant amount of phytate is still present on the excreta (Dao 2007). This may be due to phytate chelation by metals (Dao 2003) and an insufficient digestion time associated with a high phytate content in grain-based diets (Dao 2007). Phytate-degrading bacteria are also present during the fermentation of cattle manure, which suggests further degradation of phytate (Fuentes et al., 2009). Our findings suggest that even after stabilization of the used manure, there is still a significant amount of Po labile to the BPP produced by the Bacillus sp. MQH-19 and other native phytase-producing microorganisms.
Our results showed that the prevalence of Bacillus sp. MQH-19 decreased during incubation. Inoculated microorganisms are often unable to survive due to competition with pre-existing microbiota (Glick 1995; Wiehe and Hoflich 1995). It is noteworthy that our manure inoculation assay was performed under unbuffered and unsterile conditions, and inoculants had to compete with native microorganisms for colonization and survival. On the other hand, we have previously described that the addition of fresh phytate to soil induces the abundance and expression of Bacillus BPP genes contained in unknown indigenous bacteria in the rhizosphere of pastures grown in Chilean Andisol (Jorquera et al., 2013). Independent of inoculation, the addition of fresh phytate increased the Pi content in manure (UM+P and $\mathrm{IM}+\mathrm{P})$ after 6 days of incubation compared with manure without phytate addition (UM and IM), particularly in inoculated manure (IM+P) with a $117 \%$ Pi increase. This result indicates that not only phytase-producing microorganisms were present in the samples before inoculation but also that the phytase from the used inoculant was more abundant and/or more efficient in hydrolyzing freshly added phytate. The DGGE analysis also showed that enrichment by the addition of soil bacterial culture produces changes within bacterial communities. However, these changes do not necessarily indicate that native bacteria can hydrolyze phytate. Opportunistic growth may occur in response to small amounts of $\mathrm{P}$ released from phytate by the microbial community during enrichment culture. Therefore, it can be hypothesized that a small increase of Pi in manure could naturally occur by activity of native bacteria stimulated by phytate addition, and this effect could be greatly enhanced by the inoculation of phytase-producing bacteria. However, phytase genes in numerous phytate-utilizing bacteria isolated from diverse Chilean ecosystems and agro-ecosystems 
have hardly been detected by PCR, which indicates that the current database and current PCR primer sets for bacterial phytases are insufficient to provide adequate coverage of phytase genes across bacterial phyla in Chilean soils (Jorquera et al., 2014).

\section{Conclusions}

Cattle manure inoculated with a native phytaseproducing bacterium is a promising approach to increase organic phosphorus hydrolysis and the fertilizer value of organic wastes, such as animal manures. Bacillus sp. MQH-19 was found suitable to be used as an inoculant for animal manure. A significant inorganic Pi increase (8-13\%) was observed when manure was inoculated with Bacillus sp. MQH-19. However, the inoculum prevalence decreased during the experiment. The highest Pi increase (15-117\%) was observed in inoculated manure supplemented with phytate, which suggests the stimulation of native phytaseproducing microorganisms present in manure. Further studies are necessary to improve the efficiency and survival of the inoculated bacterium and to identify the native microorganisms stimulated by phytate addition.

\section{Acknowledgments}

This study was supported by Fondecyt projects no. 1120505 and 1141247. D. Menezes-Blackburn acknowledges the Chilean Doctoral Scholarships (Universidad de La Frontera and Chilean National Council for Science and Technology, CONICYT) and Georg Forster Research Postdoctoral Fellowship (Humboldt Foundation). M.A. Jorquera thanks the International Cooperation Project CONICYT-DAAD (codePCCI 1-2011).

\section{References}

Abelson, P.H. 1999. A potential phosphate crisis. Science. 283, 2015.

Acuña, J., Jorquera, M.A., Martinez, O., MenezesBlackburn, D., Fernandez, M.T., Marschner, P., Greiner, R, Mora, M.L. 2011. Indole acetic acid and phytase activity produced by rhizosphere bacilli as affected by $\mathrm{pH}$ and metals. J. Soil Sci. Plant Nutr. 11, 1-12.

Ajiboye, B., Akinremi, O.O., Racz, G.J. 2004. Laboratory characterization of phosphorus in fresh and oven-dried organic amendments. J. Environ Qual. 33, 1062-1069.

Dao, T. 2003. Polyvalent cation effects on myoInositol Hexa kis dihydrogenphosphate enzymatic dephosphorylation in dairy wastewater. J. Environ Qual. 32, 694-701.

Dao, T. 2007.Ligand effects on inositol phosphate solubility and bioavailability in animal manures. In: Turner, B.L, Richardson, A.E, Mullaney, E.J (ed). Inositol Phosphates: Linking Agriculture and the Environment. P. 169.

Fuentes, B., Jorquera, M., Mora, M.L. 2009. Dynamics of phosphorus and phytate-utilizing bacteria during aerobic degradation of dairy cattle dung. Chemosphere. 74, 325-331.

George, T.S., Simpson, R.J., Hadobas, P.A, Marshall, D.J., Richardson, A.E 2007. Accumulation and phosphatase-lability of organic phosphorus in fertilised pasture soils. Crop and Pasture Science. $58,47-55$.

Glick, B.R. 1995. The enhancement of plant growth by free-living bacteria. Can. J. Microbiol. 41, 109-117. 
Green, V., Dao, T., Stone, G., Cavigelli, M., Baumhardt, R., Devine, T. 2007. Bioactive phosphorus loss in simulated runoff from a phosphorus-enriched soil under two forage management systems. Soil Sci. 172, 721-732.

Greiner, R., Konietzny, U. 2011. Phytases: Biochemistry, enzymology, and characteristics relevant to animal feed use. In: Bedford, M, Patridge, G (ed). Enzymes in Farm Animal Nutrition., 2nd edn. CABI International, Wallingford, UK, pp. 96-128.

He, Z., Toor, G.S., Honeycutt, C.W., Sims, J.T. 2006. An enzymatic hydrolysis approach for characterizing labile phosphorus forms in dairy manure under mild assay conditions. Bioresour Technol. 97, 1660-1668.

Hedley, M., Stewart, J., Chauhan, B. 1982. Changes in inorganic and organic soil phosphorus fractions induced by cultivation practices and by laboratory incubations. Soil Sci. Soc. Am. J. 46, 970-976.

Iwamoto, T., Tani, K., Nakamura, K., Suzuki, Y., Kitagawa, M., Eguchi, M., Nasu, M. 2000. Monitoring impact of in situ biostimulation treatment on groundwater bacterial community by DGGE. FEMS Microbiol. Ecol. 32, 129-141.

Jorquera, M., Martinez, O., Maruyama, F., Marschner, P., Mora, M.L. 2008a. Current and future biotechnological applications of bacterial phytases and phytase-producing bacteria. Microbes and Environments. 23, 182-191.

Jorquera, M.A., Crowley, D.E., Marschner, P., Greiner, R., Fernandez, M.T., Romero, D., Menezes-Blackburn, D., Mora, M.L. 2011. Identification of $\mathrm{B}$ propeller phytase encoding genes in culturable Paenibacillus and Bacillus spp. from the rhizosphere of pasture plants on volcanic soils. FEMS Microbiol. Ecol. 75, 163172.
Jorquera, M.A., Hernandez, M., Martinez, O., Marschner, P., Mora, M.L. 2010. Detection of aluminium tolerance plasmids and microbial diversity in the rhizosphere of plants grown in acidic volcanic soil. Eur. J. Soil Bio. 46, 255-263.

Jorquera, M.A., Hernandez, M.T., Rengel, Z., Marschner, P., Mora, M. 2008b. Isolation of culturable phosphobacteria with both phytatemineralization and phosphate-solubilization activity from the rhizosphere of plants grown in a volcanic soil. Biol. Fertility Soils. 44, 1025-1034.

Jorquera, M.A., Inostroza, N.G., Lagos, L.M., Barra, P.J., Marileo, L.G., Rilling, J.I., Campos, D.C., Crowley, D.E., Richardson, A.E., Mora, M.L 2014. Bacterial community structure and detection of putative plant growth-promoting rhizobacteria associated with plants grown in Chilean agroecosystems and undisturbed ecosystems. Biol. Fertility Soils. 1-13.

Jorquera, M.A., Saavedra, N., Maruyama, F., Richardson, A.E., Crowley, D.E., Catrilaf, R., Henriquez, E.J., Mora, M. 2013. Phytate addition to soil induces changes in the abundance and expression of Bacillus $\beta$-propeller phytase genes in the rhizosphere. FEMS Microbiol. Ecol. 83, 352-360.

Lei, X.G., Porres, JsM. 2003.Phytase enzymology, applications, and biotechnology. Biotechnol. Lett. 25, 1787-1794.

Martinez, O.A., Jorquera, M.A., Crowley, D.E., Mora, M. 2011. Influence of nitrogen fertilisation on pasture culturable rhizobacteria occurrence and the role of environmental factors on their potential PGPR activities. Biol. Fertility Soils. 47, 875-885. 
Menezes-Blackburn, D., Greiner, R. 2014. Enzymes used in animal feed: leading technologies and forthcoming developments. In: Cirillo, G, Spizzirri, G, Lemma, F (ed). Functional Polymers in Food Science.Wiley, Calabria. pp 47-53.

Menezes-Blackburn, D., Jorquera, M., Gianfreda, L., Rao, M., Greiner, R, Garrido, E., Mora, M.L. 2011. Activity stabilization of Aspergillus niger and Escherichia coli phytases immobilized on allophanic synthetic compounds and montmorillonite nanoclays. Bioresour Technol. 102, 9360-9367.

Menezes-Blackburn, D., Jorquera, M.A., Gianfreda, L., Greiner, R., Mora, M.L. 2014. A novel phosphorus biofertilization strategy using cattle manure treated with phytase-nanoclay complexes. Biol Fertil Soils. 50, 583-592.

Menezes-Blackburn, D., Jorquera, M.A., Greiner, R., Gianfreda, L., Mora, M.L. 2013. Phytases and phytase-labile organic phosphorus in manures and soils. Crit Rev Environ Sci. Technol. 43, 916-954.

Richardson, A.E., George, T.S., Jakobsen, I., Simpson, R.J. 2006. Plant Utilization of Inositol Phosphates. In: Turner, B.L, Richardson, A.E., Mullaney, E.J. (ed). Inositol phosphates: Linking agriculture and the environment. CABI, p 242.
Smith, J.L., Collins H.P. 2007. Management of organisms and their processes in soils. In: Paul EA (ed). Soil Microbiology Ecology and Biochemistry, third edn. Elsevier Ltd, Burlington, MA, USA, pp 471-502.

Sparks, D.L., Page, A.L., Helmke, P.A., Loeppert, R.H., Soltanpour, P.N., Tabatabai, M.A., Johnston, C.T., Sumner, M.E. 1996. Methods of soil analysis. Part 3-Chemical methods Soil Science Society of America Inc. p 1309

Suzuki, M.T., Taylor, L.T., DeLong, E.F. 2000. Quantitative analysis of small-subunit rRNA genes in mixed microbial populations via 5'-nuclease assays. Appl. Environ Microbiol. 66, 4605-4614.

Wiehe, W., Hoflich, G. 1995. Survival of plant growth promoting rhizosphere bacteria in the rhizosphere of different crops and migration to non-inoculated plants under field conditions in north-east Germany. Microbiol. Res. 150, 201-206.

Zayed, G., Abdel-Motaal, H. 2005. Bio-active composts from rice straw enriched with rock phosphate and their effect on the phosphorous nutrition and microbial community in rhizosphere of cowpea. Bioresour. Technol. 96, 929-935. 